\title{
Emergence of the damselflies, Coenagrion mercuriale and Ceriagrion tenellum (Odonata: Coenagrionidae), at their northern range margins, in Britain
}

\author{
BETHAN V. PURSE and DAVID J. THOMPSON \\ Population and Evolutionary Biology Research Group, Nicholson Building, University of Liverpool, School of Biological Sciences, \\ Liverpool, L69 3GS, UK; e-mail: beth.purse@ bbsrc.ac.uk
}

Key words. Odonata, emergence, seasonal regulation, Coenagrion mercuriale, Ceriagrion tenellum

\begin{abstract}
Emergence of Coenagrion mercuriale and Ceriagrion tenellum was examined in a mixed population at their northern range margin in Britain. Mortality at emergence was quantified in $C$. mercuriale. Consistent with their larval diapause characteristics, both species had an asynchronous emergence pattern, typical of "summer" species. Daily emergence of $C$. mercuriale was positively correlated with the duration of sunlight on the previous day (controlling for season) and its emergence period was found to be shorter than that observed in its core populations in Central and Mediterranean Europe. No differences were found between the patterns of emergence of the sexes in either species. Sex ratio at emergence differed significantly from 1:1 (at $1.35: 1$ males : females) in C. mercuriale but not in Ceriagrion tenellum (at $1.04: 1$ ). Body size at emergence declined more steeply with time in females than in males of $C$. mercuriale because large size may confer a greater reproductive advantage in females (larger females may be more fecund) than males in non-territorial odonates. Percentage mortality of $C$. mercuriale at emergence was low ( $4.9 \%$ including deformed individuals), the main cause of mortality being deformity.
\end{abstract}

\section{INTRODUCTION}

Odonates are almost exclusively aquatic in their larval stages and metamorphosis to the adult stage includes a niche shift from the aquatic to the terrestrial habitat (Corbet, 1980). Examination of odonates at emergence allows sex ratio, mean body size, numbers and seasonal patterns to be investigated before any bias by dispersal or differential adult mortality appears (Michiels \& Dhondt, 1989).

Seasonal regulation is the restriction of development to a particular season through an array of responses (Corbet, 1999). In temperate region odonates, the emergence period is restricted (Corbet, 1980) despite differences in development rate accumulated between individuals in the larval stage due to differential hatch dates (Johanson, 1991) or differences in the nutritional condition of individuals (e.g. Harvey \& Corbet, 1985). This restriction is achieved by diapause characteristics in the larvae, by the distinct responses to critical day length and temperature of different instars (Corbet, 1957a; Sternberg, 1994). Corbet (1954) distinguished between populations that overwinter (and diapause) in the final instar and have a closely synchronised and often early emergence ("spring" species) and those that overwinter in one or more earlier stadia, have less well synchronised emergence and emerge later ("summer species").

Since odonates are poikilothermic and of tropical origin (Krishnaraj \& Pritchard, 1995; Sternberg, 1994), their distribution, seasonality and inter-habitat variation are strongly restricted by climatic factors, especially temperature (May, 1978). In other insect taxa, such as Lepidoptera, species often occupy narrower niches within biotopes towards the edges of their ranges (Thomas et al., 1999). Crowley \& Johnson (1982a) found that some odo- nate species had shorter flight periods at their range margins than in the centre.

Coenagrion mercuriale (Charpentier) is listed as rare (category 3) on the UK red list and is the target of a UK Biodiversity Action Plan (HMSO, 1984). It has vanished, or is on the edge of extinction, in seven countries along the northern and eastern boundaries of its distribution in Europe (Belgium, Holland, Luxembourg, Slovenia, Romania, Poland, Austria - Grand, 1996). Ceriagrion tenellum (Villers) is listed as scarce on the UK red list but is widespread in Europe (Brooks \& Lewington, 1997). The aim of this study was to investigate the effect of season and climatic factors on the form of the emergence curve in these two rare damselflies that reach their northern range margins in Britain $\left(50-53^{\circ} \mathrm{N}, 1-2^{\circ} \mathrm{W}\right)$. Their emergence patterns are compared to those found in core European populations, in Germany $\left(47-49^{\circ} \mathrm{N}\right.$, $\left.10-12^{\circ} \mathrm{E}\right)$, France $\left(42-48^{\circ} \mathrm{N}, 4-8^{\circ} \mathrm{E}\right)$ and the Mediterranean $\left(37-43^{\circ} \mathrm{N}, 3-9^{\circ} \mathrm{E}\right)$, and related to the diapause characteristics in larvae. Both species are semi-voltine in Britain.

The survival of a species depends on the sequential survival of successive developmental stages (Samways, 1994). For rare odonates, survival through emergence is particularly worthy of investigation since it has been suggested that this may be a period of substantial mortality (Crowley et al., 1987). This life-history stage is concentrated in space and time and emerging individuals are immobile and defenceless (Corbet, 1962). Possible mortality factors at emergence include competition for perches, predation (e.g. Bennett \& Mill, 1993) and desiccation or deformation due to strong winds or low temperatures (e.g. Jakob \& Suhling, 1999). Thus for $C$. mercuriale, the rarer species, mortality at emergence was also quantified. 


\section{MATERIALS AND METHODS}

The $250 \mathrm{~m}$ stretch of study stream was located at Upper Crockford on Beaulieu Heath, New Forest, south-east England (SU $350990,51^{\circ} \mathrm{N}, 1^{\circ} \mathrm{W}$ ). The stream ran through valley mire with some areas of wet heath, and was surrounded by humid and dry heath. It ranged from 5 to $20 \mathrm{~m}$ in width and from 0.05 to 1 $\mathrm{m}$ in depth. Stream vegetation was dominated by soft herbs including Hypericum elodes, Potamogeton polygonifolius, Drosera rotundifolia, Juncus sp. and Sphagnum sp., whilst bankside vegetation was dominated by Carex sp. Juncus sp. Myrica gale, Molinia caerulea, Erica tetralix and Ulex galli.

On heathlands, Coenagrion mercuriale and Ceriagrion tenellum emerge in unshaded, shallow areas of short emergent vegetation (species such as Juncus articulatus and Eleocharis palustris). Intervening areas of dense, tussocky vegetation make exuviae difficult to find. Thus, emergence cages were used to enclose a fixed area of emergence habitat on the stream and allowed a standard proportion of the emerging adult population to be collected each day. Each cage consisted of a light, A-frame covered by transparent, fine mesh netting and covered an area of $0.72 \mathrm{~m}^{2}$. Fifteen emergence cages were anchored to the substrate along the stream. Cages 1 to 10 were in place from 24 May - to 9 August and cages 11-15 from 9 June to 9 August. Between these dates, cages were checked daily, in the afternoon, for newly emerged individuals (tenerals). Tenerals of C. mercuriale were removed, transferred to gauze-covered pots and retained overnight to allow them to harden. To measure body size, left forewing length was measured ( $c f$. Banks \& Thompson, 1985; Fincke, 1982) $\pm 0.01 \mathrm{~mm}$ with digital callipers. Each teneral was given a unique mark consisting of a combination of a dot of Tippex on the thorax and a felt tip pen number on the left forewing. They were released the next morning outside the cage in which they had been caught to avoid artificially increasing the density of individuals at one position on the site. Tenerals of $C$. tenellum were not retained but were sexed and released onto surrounding vegetation. The cause of any deaths or deformity in cages was noted for C. mercuriale and dead individuals were removed daily. Whilst deformities may be genetic, those occurring at emergence arise when the teneral is physically disturbed by strong wind or rain or by intraspecific competition for emergence perches (Corbet, $1957 \mathrm{~b})$ whilst its body is still hardening. In addition, low temperatures cause incomplete ecdysis (Corbet, 1957b). Deaths whilst hardening in pots before marking were omitted from estimates of mortality at emergence

A mark-recapture exercise was carried out every day by searching the stream and roosting areas of humid heath vegetation within $10 \mathrm{~m}$ of the stream for adults [(reducing the potential bias resulting from sex or age differences in habitat use (Fincke, 1986)]. The identity and state of maturity (teneral or adult, ascertained by the paler colouration of the former) of adults were noted to provide information on the length of the prereproductive adult period.

To compare synchronisation of emergence between the two species, $\mathrm{EM}_{50}$ was calculated. This is the time (in days since emergence began) by which $50 \%$ of the annual population has emerged (Taketo, 1960).

Data from a British Atmospheric Data Centre meteorological station in Everton (SZ302937, $7 \mathrm{~km}$ southwest of the study site) were used to generate the following normal weather variables for a $24 \mathrm{~h}$ period (variable codes are given in parentheses, starred variables were log-transformed): Duration of sunshine in hours (Sun), amount of precipitation in $0.1 \mathrm{~mm}$ (Lrain)*, minimum temperature in $0.1^{\circ} \mathrm{C}$ (Mint), maximum temperature in $0.1^{\circ} \mathrm{C}$ (Maxt), duration of sunshine in previous $24 \mathrm{~h}$ period in hours (Sun prev), amount of precipitation in previous 24 hour period in $0.1 \mathrm{~mm}$ (Lrain Prev)*, minimum temperature in previous 24 hour period in $0.1^{\circ} \mathrm{C}$ (Mint Prev), maximum temperature in previous $24 \mathrm{~h}$ period in $0.1^{\circ} \mathrm{C}$ (Maxt Prev).

To investigate the effect of these weather variables on daily emergence whilst controlling for season, residual numbers of $C$. mercuriale emerging each day (Resid E) were obtained from a regression of numbers emerging (No. E) on day of emergence (i.e. time in days since emergence began in $C$. mercuriale). The same analysis was not performed for $C$. tenellum since numbers emerging could not be normalised by any transformation. Since, weather variables were likely to show multicolinearity, residuals were regressed against the eight weather variables using a forward stepwise regression procedure. This procedure tests the parameter associated with each variable in the presence of all variables already in the model (Mendenhall \& Sincich, 1996; Trexler \& Travis, 1993). The criterion for addition of a variable to the model was that the significance of the F-value was less than 0.05 . The criterion for removal of a variable was that the significance of the F-value was more than 0.10 .

Mean body size (left forewing length, log-transformed) was compared between male and female tenerals (sex) using an analysis of covariance (ANCOVA) with day of emergence (day) as the covariate. This enabled both difference in body size between males and females and the significance of any decrease in body size through time to be evaluated.

\section{RESULTS}

\section{Emergence pattern and sex ratio at emergence}

Numbers of $C$. mercuriale and $C$. tenellum emerging each day throughout the season (Cages 1-10) are shown in Fig. 1. $24^{\text {th }}$ May is referred to as Day 1 of the season for both species. The duration of emergence was 60 days for male $C$. mercuriale (days 1-60) and 63 days for females (days 1-63). The day of peak emergence was day 23 (i.e. 15 June), and $\mathrm{EM}_{50}$ was day 22. The duration of emergence of $C$. tenellum was shorter than that for $C$. mercuriale at around 50 days and began later, on day 20 . Day 50 and 56 (12 and 18 July) were days of peak emergence. $\mathrm{EM}_{50}$ was 30 (day 50). The shapes of their emergence curves (Komologorov-Smirnov, $z=7.9, p<0.001$ ) and the median day of their emergence differed significantly between the two species ( $C$. mercuriale - median $=$ day 23 ; $C$. tenellum - median $=$ day 47.5 ; Wilcoxon twosample test, $W=143999, p=0.653$ ).

The sex-ratio of $C$. mercuriale at emergence, at $1.35: 1$ (293 males : 217 females - cages 1-15), was significantly different from $1: 1\left(c^{2}=11.33,1\right.$ d.f., $\left.p<0.005\right)$. However, the sex ratio of $C$. tenellum at emergence, at $1.04: 1$ (119 : 115 - cages $1-15$ ), was not significantly different from $1: 1\left(\mathrm{c}^{2}=0.02,1\right.$ d.f., $\left.p=0.90\right)$.

Median day of emergence did not differ between the sexes for either $C$. mercuriale (males - median $=$ day 23 ; females - median $=$ day 24 ; Wilcoxon two-sample test, $W$ $=74443, p=0.8$ ) or C. tenellum (males - median $=$ day 47; females - median $=$ day 48 ; Wilcoxon two-sample test, $W=14215, p=0.65$ ). Furthermore, the shapes of the emergence curves did not differ between males and females for $C$. mercuriale (Komolgorov-Smirnov, $Z=$ 1.03, $p=0.24, n_{1}=293, n_{2}=217$ ) or for $C$. tenellum (Komolgorov-Smirnov, $Z=0.54, p=0.93, n_{1}=119, n_{2}=$ 115). 
(a)

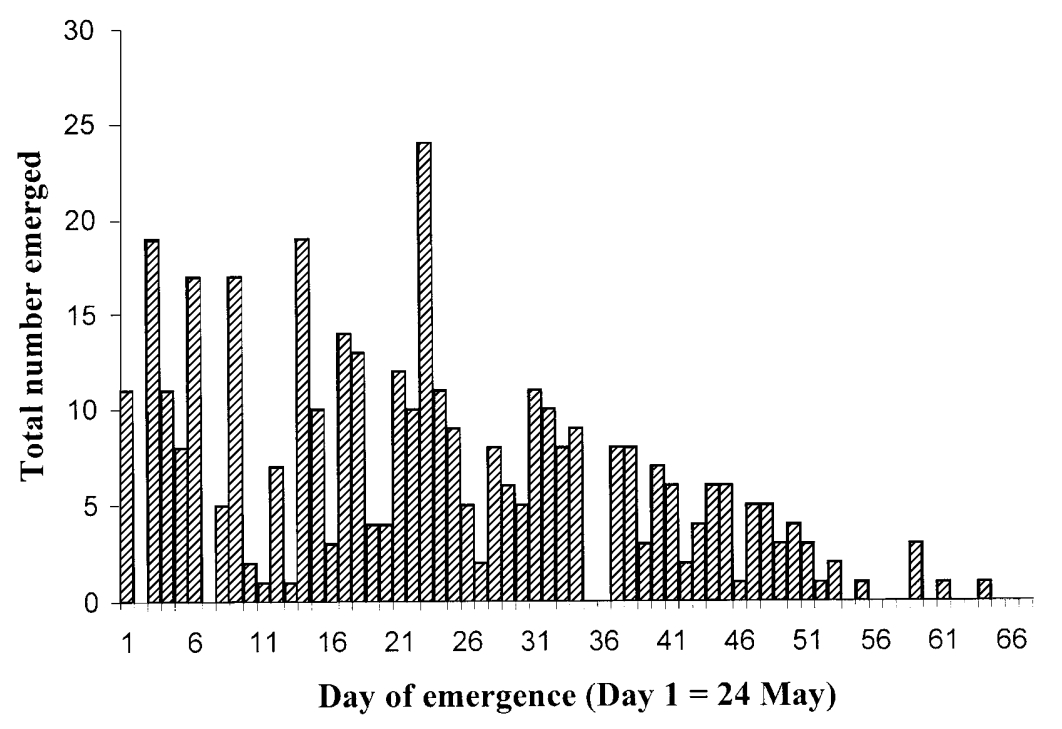

(b)

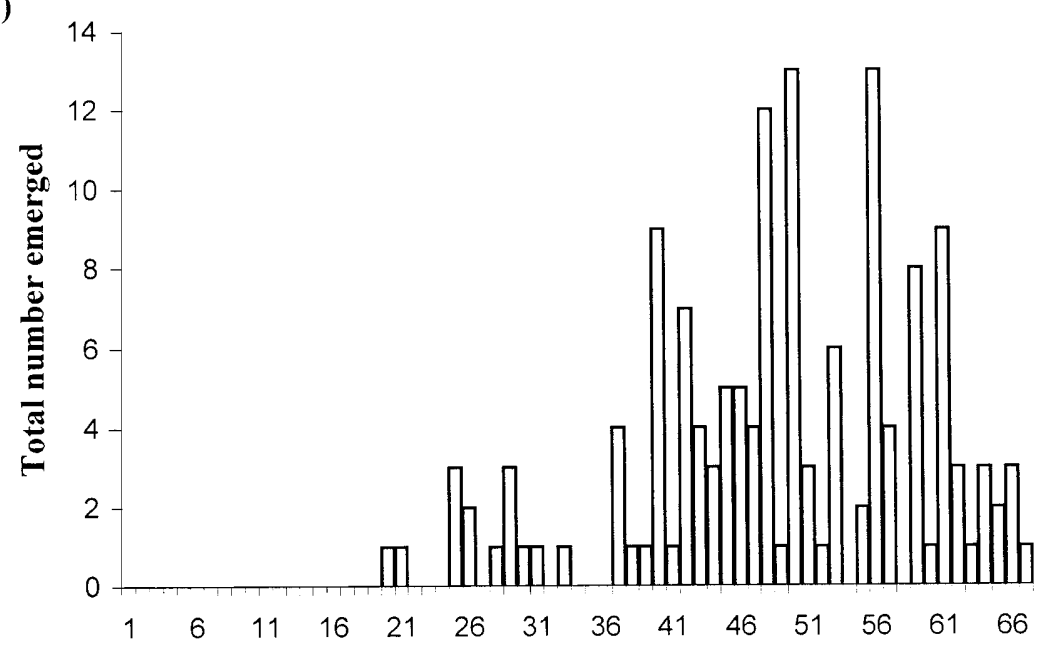

Day of emergence (Day $1=24$ May)

Fig. 1. The daily emergence of (a) Coenagrion mercuriale and (b) Ceriagrion tenellum in 1999 (from cages 1-10).

\section{Effect of season and climatic variables on daily emergence in $C$. mercuriale}

A significant positive relationship was found between the number of individuals emerging and day of emergence for $C$. mercuriale $\left(F=60.4, p<0.001, R^{2}=0.55\right)$. The duration of sunlight in the previous $24 \mathrm{~h}$ (Sun Prev) showed a significant positive relationship with residual daily emergence of $C$. mercuriale but overall the model was not very strong (Resid $\mathrm{E}=-4.92+0.065^{*}$ Sun Prev, $\mathrm{R}^{2}=0.258, \mathrm{~F}_{1,34}=11.85, \mathrm{p}=0.002$ ). However, when the number of emerging $C$. mercuriale was regressed against day of emergence (Day) and Sun Prev (using an "enter" multiple regression where all variables are forced into the model), the regression model accounted for $64.3 \%$ of the variation in daily emergence (No. $\mathrm{E}=18.76-0.36^{*}$ Day $+0.045^{*}$ Sun Prev, $\left.\mathrm{R}^{2}=0.643, \mathrm{~F}_{2,49}=42.26, \mathrm{p}<0.001\right)$. This suggests that both amount of sunlight and day of emergence were important in determining daily emergence in C. mercuriale.

\section{Body size at emergence in $C$. mercuriale}

A significant interaction was found between sex and day of emergence in their effect on body size at emergence in C. mercuriale (Ancova; $\mathrm{F}_{\text {model }}=261.1,3$ d.f., $\mathrm{p}<$ $0.001, \mathrm{R}^{2}=0.63, \mathrm{~F}_{\mathrm{sex}^{*} \mathrm{day}}=10.1, \mathrm{p}<0.002, \mathrm{~F}_{\mathrm{sex}}=299.7$, $\mathrm{F}_{\text {day }}=25.5$ ). Mean body size of females was larger than males and body size decreased significantly with time (day of emergence). Body size decreased more rapidly with time in females than in males (Fig. 2).

\section{Mortality at emergence in $C$. mercuriale}

The total percentage mortality of tenerals at emergence was low at $1.6 \%$ (8 out of 510 individuals found in cages) and was due to a range of causes. Three individuals had been predated on by spiders, one was waterlogged and four individuals were deformed, having crumpled wings or bent abdomens. Some of the tenerals found alive in cages were also deformed. The total deformed proportion of the teneral adult population (22 out of 510) was signifi- 


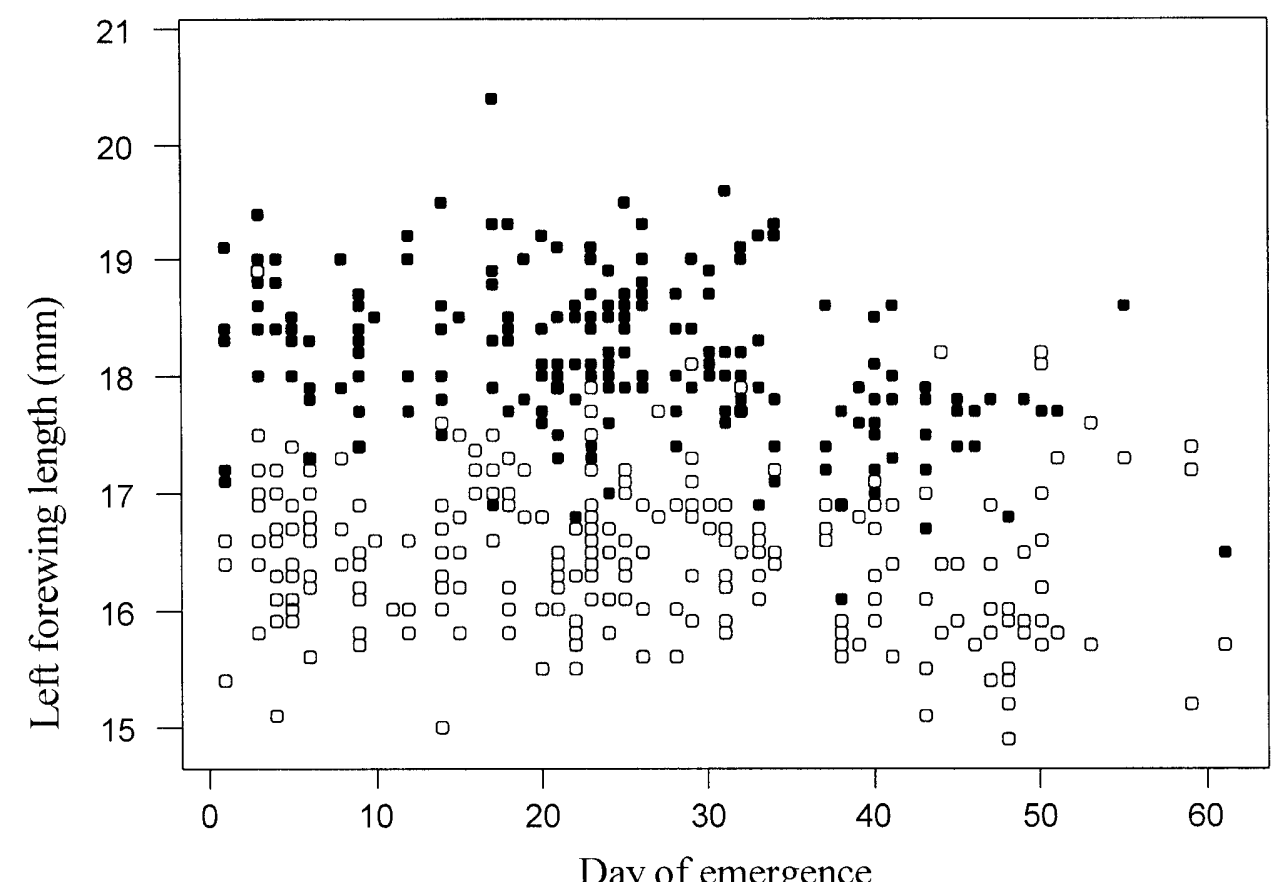

Fig. 2. Relationship between body size and day of emergence for male (open circles) and female (closed circles) tenerals of Coenagrion mercuriale.

cantly larger than the deformed proportion of the mature adult population (7/2694) $\left[\mathrm{c}^{2}=74.032,1\right.$ d.f, $p<0.001$ (Yates correction)], suggesting that deformed individuals are unlikely to survive to sexual maturity. If so, the 17 individuals that were deformed but did not die at emergence probably died soon afterwards, increasing the percentage mortality at emergence to $4.9 \%(25 / 510)$.

\section{Length of the maturation period in $C$. mercuriale}

Since only $4.8 \%$ (22 out of 462 ) of marked tenerals were recaptured as mature adults, it was not possible to estimate the mean length of the maturation period in $C$. mercuriale. Many individuals marked at emergence were not recaptured on the first day of sexual maturity. However, all individuals recaptured 8 days or more after emergence were sexually mature and one individual matured in 5 days.

\section{DISCUSSION}

Both $C$. mercuriale and $C$. tenellum show a nonsynchronous emergence pattern, typical of "summer" species. $\mathrm{EM}_{50}$ was similar to values for other "summer" species such as Aeshna cyanea $\left(\mathrm{EM}_{50}=25\right.$, Corbet, 1962). In contrast, in a "spring" species, Lestes rectangularis EM $_{50}$ was 7 days (Gower \& Kormondy, 1963). These asynchronous emergence patterns arise because the $2^{\text {nd }}$ year age group of both species overwinters in a range of instars (antepenultimate, penultimate and final instars) in Britain (Corbet, 1957a; Purse \& Thompson, 2002). Indeed, in a larval population of $C$. mercuriale on Mynydd Preseli, South Wales, $67 \%$ of the $2^{\text {nd }}$ year larvae were still in the antepenultimate and penultimate instars when emergence began (Purse \& Thompson, 2002).
Emergence of $C$. mercuriale was slightly more synchronised than in C. tenellum, since, in Britain, a higher proportion of $C$. mercuriale than $C$. tenellum overwinter in the penultimate instar (Corbet, 1957a) and thus only had to pass through two stadia before emergence.

In odonates, although the potential emergence pattern is determined by the mode of seasonal regulation, the actual pattern depends on proximate climatic factors including temperature (Corbet, 1957b; Gribbin \& Thompson, 1990; Lutz, 1968), and wind speed (Jakob \& Suhling, 1999). Having controlled for the effect of season, the extent of daily emergence in C. mercuriale depended on the duration of sunlight on the previous day. In the small, unshaded, slow-flowing water bodies inhabited by $C$. mercuriale in Britain (pers. obs.) and Europe (Buchwald, 1994), there is no thermal lag between ambient and water temperatures such that the probability that suitable temperatures for emergence or hardening are reached and maintained depends directly on the daily level of insolation. Similarly, a positive relationship between sunlight and daily emergence was found in Lestes eurinus populations in small, shallow ponds (Lutz, 1968). Emergence in odonates proceeds more quickly at higher temperatures (e.g. Ubukata, 1973) and it may be adaptive for individuals to postpone emergence until temperatures are high and stable to reduce the risk of predation during hardening. There is some evidence that $C$. mercuriale may be able to postpone emergence (for considerable periods) following metamorphosis. In some individuals, the adult labium has been found retracted in the larval prementum for three weeks before emergence, a condition that lasts only 2 to 3 days in most odonates (Corbet, 1955). Although sometimes cited as causes of mortality at 
emergence, wind (speed) and rainfall were not important factors in determining daily numbers of adults emerging in the present study. Since the cages were made of very fine but widely spaced mesh, it is unlikely that they reduced the effect of wind and rain in this study.

The dependence of emergence on temperature restricts the temporal niche of $C$. mercuriale within its annual season (as well as within a day) on the edge of its range. In most regions of Britain $\left(50-53^{\circ} \mathrm{N}, 1-2^{\circ} \mathrm{W}\right)$, the flight period lasts from late May to early August (Colley \& Howe, 1999; Jenkins, 1986; pers. obs.) whilst the flight period in core populations in the Mediterranean (Spain and Portugal, $37-43^{\circ} \mathrm{N}, 3-9^{\circ} \mathrm{E}$ ) is much longer, lasting from early April to early November (Grand, 1996 and refs therein). In other edge of range alpine populations in Germany $\left(47^{\circ} \mathrm{N}, 11^{\circ} \mathrm{E}\right)$, the flight period lasts from midJune to mid-August (Sternberg et al., 1999). Such widening of temporal niches in favourable climates is common in odonates (Crowley \& Johnson, 1982a; Sternberg, 1994). For C. tenellum, there is a paucity of data on flight periods in core populations. In Britain, the flight period is said to begin in early June and continue until late August (Brooks \& Lewington, 1997). The flight period observed in our study was shorter, perhaps indicating that the final days of emergence were missed and therefore $\mathrm{EM}_{50}$ may have been underestimated.

This study examined only one year's emergence period of these two species. It should be noted that, as in other odonates (cf. Benke \& Benke, 1975), C. mercuriale shows considerable variation in flight period between years in Britain (D. K. Jenkins, pers. comm) that is attributable to wide variation in climatic conditions between years. Flight periods are likely to show wider variation in flight period in populations at the edge versus the core of a species' range due to the generally wider annual variation in climatic conditions experienced by the former.

Differences in emergence patterns of the two species observed here are attributable to species-specific temperature thresholds for development (Sternberg, 1994). Since these species overlap considerably in their use of oviposition and emergence habitat (pers. obs.), there may be selection for temporal separation of their emergence periods to avoid interspecific competition between adults (cf. Benke \& Benke, 1975; Crowley \& Johnson, 1982b; Johannsson, 1978; Sternberg, 1994). Controlled field and laboratory experiments are required to tease out the relative roles of climatic and biotic factors (such as interspecific competiton) in determining emergence pattern in different populations.

Consistent with findings for most odonate species (Corbet, 1999), no difference was found between sexes in the pattern of emergence for either species. In common with other zygopterans (Corbet \& Hoess, 1998), the sex ratio of $C$. mercuriale at emergence differed significantly from $1: 1$, with males making up $57.4 \%$ of the study population. No such difference was found for $C$. tenellum. The sex-determination mechanism in odonates predicts a sex ratio of unity in the zygote (Kiauta, 1969) such that sex ratio imbalances at emergence can be attributed to differ- ential mortality of eggs and/or larvae. Size-selective predation on larger female larvae has been postulated as a possible source of mortality. Although females are significantly larger than males in adult (controlling for emergence date) and larval C. mercuriale, male biased sex ratios were not observed in larval instars in a different British population (Purse \& Thompson, 2002). Data on consecutive larval and emerging adult stages from a range of populations under different predator pressure are required to determine whether male-biased sex ratios occur consistently in this species at emergence. However, the effect of such a small bias in sex ratio on the reproductive potential of the adult population is unlikely to be significant (Corbet \& Hoess, 1998).

Large individuals emerged early in the season and small individuals emerged later in C. mercuriale, and size at emergence declined more steeply with time in females than in males. A comparable negative relationship has been described in many temperate odonate species (Banks \& Thompson, 1985; Corbet, 1999; Michiels \& Dhondt, 1989) and other insects with complex life cycles (Rowe \& Ludwig, 1991), but few have found a difference in its slope between sexes. Rowe \& Ludwig (1991) suggested there may be a trade-off between gaining mass and delaying reproduction. Since the relative benefits of gaining further mass at a given time decrease with current mass, large larvae tend to emerge earlier than small ones. In contrast, early in the season, it is beneficial for small larvae to attain more mass and to pay the costs of delayed reproduction. Later in the season, costs (such as exclusion from preferred refuges/oviposition sites by larger conspecifics and increased likelihood of predation in the larval stage) outweigh the benefits of mass gain. A steeper decline in size at emergence with time might be expected if the fitness differential between large and small females is greater than that between large and small males. This may arise in non-territorial odonates with scramble competition (such as C. mercuriale) where large size does not confer a reproductive advantage but where females with larger abdomens may produce larger clutches. In contrast, in territorial odonates, where large size confers a reproductive advantage in both sexes (Anholt et al., 1991), no sex difference in the slope of the relationship between size and emergence date is expected.

Percentage mortality of $C$. mercuriale at emergence (4.9\% including deformed individuals) was low compared with many other odonate studies for which estimates range from 3.3\% (Bennett \& Mill, 1993) to 28\% (Gribbin \& Thompson, 1991). Causes of mortality in C. mercuriale included incomplete ecdysis or failure to expand wings, predation by spiders and water-logging. Although, in our study, predation by birds would have been reduced by the presence of cages, few birds have been considered responsible for high mortality in odonate populations (Corbet, 1999). It is probable that mortality at emergence is likely to have a less significant effect on population density or dynamics of C. mercuriale than that occurring in other life stages such as the egg, larval or immature adult stages ( $c f$. Ubukata, 1981). 
As often observed in odonates (Corbet, 1980), the rate of recapture of $C$. mercuriale after marking as immature adults was very low. This may indicate that the prereproductive adult stage constitutes a period of high mortality, but is also likely to reflect the difficulty of monitoring diffuse breeding habitat in stream-dwelling odonates (Bennett \& Mill, 1995; Stettmer, 1996). The 5-8 day maturation period found in this study for $C$. mercuriale, is consistent with estimates of a 4-5 day maturation period in Baden-Wurttemburg $\left(51^{\circ} \mathrm{N}, 10^{\circ} \mathrm{E}\right.$ - Sternberg et al., 1999) and with maturation periods of other coenagrionids in Britain (e.g. 13-14 days Pyrrhosoma nymphulaBennett \& Mill, 1995). Although the data for C. mercuriale obtained in our study were minimal, given that the mean lifespan of mature adults is 6 or 7 days, the prereproductive period occupies approximately half of the adult lifespan in this species.

In conclusion, in an edge of range population of $C$. mercuriale, emergence pattern and, in turn, the width of the temporal niche for the adult stage, is governed by climatic factors as well as the mode of seasonal regulation. It is probable that the relative roles of season, climate and competition (or predation) in governing developmental pattern (and temporal niche width) will change across a species' range and between years. Decrease in microhabitat availability for poikilothermic insects has been shown as temperature decreases from range centres to Northern range margins (Hill et al., 1999; Thomas et al., 1999). It is pertinent to investigate the narrowing of temporal niches in such transitions as well, since the width of the temporal niche affects the likelihood of reproduction, migration events, and susceptibility of populations to stochastic events of different duration.

ACKNOWLEDGEMENTS. We thank the Forestry Commission for permission to work on the Crockford stream. BVP was supported by a Studentship from the Environment Agency, English Nature and the Countryside Council for Wales. Pete Smith and Charlotte Walker provided valuable assistence in the field. The work was carrided out under licence from English Nature.

\section{REFERENCES}

Anholt B.R., Marden J.H. \& Jenkins D.M. 1991: Patterns of mass gain and sexual dimorphism in adult dragonflies (Insecta: Odonata). Can. J. Zool. 69:1156-1163.

BAnKs M.J. \& Thompson D.J. 1985: Emergence, longevity and breeding area fidelity in Coenagrion puella (L.) (Zygoptera: Coenagrionidae). Odonatologica 14: 279-286.

Benke A.C. \& BENKE S.S. 1975: Comparative dynamics and life histories of co-existing dragonfly populations. Ecology 56: 302-317.

BennetT S. \& Mill P.J. 1993: Larval development and emergence in Pyrrhosoma nymphula (Sulzer) (Zygoptera: Coenagrionidae). Odonatologica 22: 133-145.

BenNett S. \& Micl P.J. 1995: Lifetime egg production and egg mortality in the damselfly Pyrrhosoma nymphula (Sulzer) (Zygoptera: Coenagrionidae). Hydrobiologia 310: 71-78.

Brooks S. \& Lewngton R. 1997: Field Guide to the Dragonflies and Damselflies of Great Britain and Ireland. British Wildlife Publishing, Hook, Hampshire, 160pp.

Buchwald R. 1994: Zur Bedeutung der Artenzusammensetzung und Struktur von Fliessgewasser-Vegetation fur die Libelle- nart Coenagrion mercuriale mit Bemerkungen zur Untersuchungsmethodik. Ber. Reinh-Tuxen-Ges. Hannover 6: 61-81.

Colley L.T. \& Howe M.A. 1999: Monitoring of the southern damselfly Coenagrion mercuriale at Nant Isaf Spring Field, Cors Erddreiniog SSSI in 1998. Countryside Council for Wales. Unpublished report.

CoRbet P.S. 1954: Seasonal regulation in British dragonflies. Nature 174: 655.

CoRBet P.S. 1955: The larval stages of Coenagrion mercuriale (Charp.) (Odonata: Coenagrionidae). Proc. Roy. Entomol. Soc., Lond. (A) 30: 115-126.

Corbet P.S. 1957a: The life histories of two summer species of dragonfly (Odonata: Coenagriidae). Proc. Zool. Soc. Lond. 128: 403-418.

CORBEt P.S. 1957b: The life-history of the emperor dragonfly Anax imperator Leach (Odonata: Aeshnidae). J. Anim. Ecol. 26: 1-69.

CORBET P.S. 1962: A Biology of Dragonflies. Witherby, London, $247 \mathrm{pp}$.

Corbet P.S. 1980: Biology of Odonata. Ann. Rev. Entomol. 25: 189-217.

CORBET P.S. 1999: Dragonflies: Behaviour and Ecology of Odonata. Harley Books, Colchester, 829 pp.

Corbet P.S. \& Hoess R. 1998: Sex ratio of Odonata at emergence. Int. J. Odonatol. 1: 99-118.

Crowley P.H. \& Johnson D.M. 1982a: Co-occurence of Odonata in the eastern United States. Advances in Odonatology 1: 15-37.

Crowley P.H. \& Johrson D.M. 1982b: Habitat and seasonality as niche axes in an odonate community. Ecology 63:1064-1077.

Crowley P.H., Nisbet R.M., Gurney W.S.C. \& Lawton J.H. 1987: Population regulation in animals with complex lifehistories: Formulation and analysis of a damselfly model. Adv. Ecol. Res. 17:1-54.

FINCKE O.M. 1982: Lifetime mating success in a natural population of the damselfly, Enallagma hageni Walsh) (Odonata: Coenagrionidae). Behav. Ecol. Sociobiol. 10: 293-302.

FINCKE O.M. 1986: Lifetime reproductive success and the opportunity for selection in a non-territorial damselfly (Odonata: Coenagrionidae). Evolution 40: 791-803.

Gower J.L. \& Kormondy E.J. 1963: Life history of the damselfly Lestes rectangularis with special reference to seasonal regulation. Ecology 44: 398-402.

GRAND D. 1996: Coenagrion mercuriale (Charpentier, 1840). In: van Helsdingen P.J., Willemse L. \& Speight M.C.D. (eds), Background Information on Invertebrates of the Habitats Directive and the Bern Convention - Part II: Mantodea, Odonata, Orthoptera, and Arachnida, Vol. 80. Council of Europe Publishing, Strasbourg, pp 245-253.

GribBin S.D. \& Thompson D.J. 1990: A quantitative study of mortality at emergence in the damselfly Pyrrhosoma nymphula (Sulzer) (Zygoptera: Coenagrionidae). Freshw. Biol. 24: 295-302.

Gribirn S.D. \& Thompson D.J. 1991: Emergence of the damselfly Pyrrhosoma nymphula (Sulzer) (Zygoptera: Coenagrionidae) from two adjacent ponds in Northern England. Hydrobiologia 209: 123-131.

HaRvey I.F. \& CoRbet P.S. 1985: Territorial behaviour of larvae enhances mating success of male dragonflies. Anim. Behav. 33: $561-565$.

Hill J.K., Thomas C.D. \& Huntley B. 1999: Climate and habitat availability determine 20 th century changes in a butterfly's range margin. Proc. Roy. Soc. Lond., Series B 266: 1197-1206. 
HMSO. 1994: Biodiversity: The UK Action Plan, pp. 188.

JАKOB C. \& SuHLING F. 1999: Risky times? Mortality during emergence in two species of dragonflies (Odonata: Gomphidae, Libellulidae). Aquatic Insects 21: 1-10.

Jenkins D.K. 1986. A population study of Coenagrion mercuriale (Charpentier) at a New Forest site using a modified "Pollard Walk". J. Brit. Dragonfly Soc. 2: 17-20.

JorAnNsson O.E. 1978: Co-existence of larval Zygoptera (Odonata) common to the Norfolk Broads (U.K.). Oecologia 32: 303-321.

Jornson D.M. 1991: Behavioural ecology of larval dragonflies and damselflies. TREE 6: 8-13.

KiAUTA B. 1969: Sex chromosomes and sex determining mechanisms in Odonata, with a review of the cytological conditions in the family Gomphidae, and references to the karyotypic evolution of the order. Genetica 40: 127-157.

Krishnaraj R. \& Pritchard G. 1995: The Influence of larval size, temperature, and components of the functional response to prey density on growth rates of the dragonflies Lestes disjunctus and Coenagrion resolutum (Insecta: Odonata). Can. J. Zool. 73: 1672-1680.

Lutz P.E. 1968: Life history studies on Lestes eurinus Say (Odonata). Ecology 49: 576-579.

MAY M.L. 1978: Thermal adaptations of dragonflies. Odonatologica 7: 27-47.

Mendenhall W. \& Sincich T. 1996: A Second Course in Statistics; Regression Analysis. 5th Edtion ed. Prentice Hall Inc. $900 \mathrm{pp}$.

Michiels N.K. \& Dhondt A.A. 1989: Effects of emergence characteristics on longevity and maturation in the dragonfly Sympetrum danae (Anisoptera: Libellulidae). Hydrobiologia 171: $149-158$.

Purse B.V. \& Thompson D.J. 2002: Voltinism and larval growth pattern in Coenagrion mercuriale (Charpentier, 1840) at its Northern range margin. Eur. J. Entomol. 99: 11-18
Rowe L. \& Ludwig D. 1991: Size and timing of metamorphosis in complex life cycles: time constraints and variation. Ecology 72: 413-427.

SAMWAYS M.J. 1994: Insect Conservation Biology. Chapman \& Hall, London, $358 \mathrm{pp}$.

STERNBERG K. 1994: Niche specialization in dragonflies. Advances in Odonatology 6: 177-198.

Sternaerg K., Buchwald R. \& Roske W. 1999: Coenagrion mercuriale (Charpentier, 1840) - Helm Azurjungfer. In: Sternberg K. \& Buchwald R. (eds), The Dragonflies of Baden Wurttemburg. Eugen Ulmer Press, Stuttgart, $468 \mathrm{pp}$.

Stettmer C. 1996: Colonisation and dispersal patterns of banded (Calopteryx splendens) and beautiful demoiselles (C. virgo) in south-east German streams. Eur. J. Entomol. 93: 579-593.

TAKeto A. 1960: Studies on the life-history of Tanypteryx pryeri Selys (Odonata, Petaluridae) I. Observations of adult dragonflies. Kontyu 28: 97-109.

Thomas J.A., Rose R.J., Clarke R T., Thomas C.D. \& Webb N.R. 1999: Intraspecific variation in habitat availability among ectothermic animals near their climatic limits and their centres of range. Funct. Ecol. 13: 55-64.

TREXLER J.C. \& TRAVIS J. 1993: Nontraditional regression analyses. Ecology 74:1629-1637.

UBUKATA H. 1973: Life history and behavior of a corduliid dragonfly, Cordulia aenea amurensis Selys. I. Emergence and prereproductive periods. J. Fac. Sci. Hokkaido Univ. Ser. Zool. VI 19: 251-269.

UBUKaTA H. 1981: Survivorship curve and annual fluctuation in the size of emerging population of Cordulia aenea amurensis Selys (Odonata: Cordullidae). Jap. J. Ecol. 31: 335-346.

Received March 1, 2002; revised July 11, 2002; accepted July 21, 2002 